\title{
Trocas gasosas e conteúdo de carboidratos e compostos nitrogenados em pinhão-manso irrigado com águas residuária e salina
}

\author{
Antonio Evami Cavalcante Sousa(1), Joaquim Albenisio Gomes Silveira(2), Hans Raj Gheyi( ${ }^{(3)}$ \\ Milton Costa Lima Neto ${ }^{(2)}$, Claudivan Feitosa de Lacerda ${ }^{(4)}$ e Frederico Antonio Loureiro Soares ${ }^{(5)}$
}

\begin{abstract}
(1) Universidade Federal de Campina Grande, Unidade Acadêmica de Engenharia Agrícola, Caixa Postal 1.0078, Avenida Aprígio Veloso, no 882, CEP 58109-970 Campina Grande, PB. E-mail: evami@ibest.com.br (2)Universidade Federal do Ceará (UFC), Departamento de Bioquímica e Biologia Molecular, Campus do Pici, Bloco 907, Caixa Postal. 6020, CEP 60451-970 Fortaleza, CE. E-mail: silveira@ufc.br, miltoncostalima@hotmail.com ${ }^{(3)}$ Universidade Federal do Recôncavo da Bahia, Núcleo de Engenharia de Água e Solo, Rua Rui Barbosa, no 710, Centro, CEP 44380-000 Cruz das Almas, BA. E-mail: hans@pq.cnpq.br (4)UFC, Departamento de Engenharia Agrícola. E-mail: cfeitosa@ufc.br

${ }^{(5)}$ Instituto Federal Goiano, Campus Rio Verde, Rodovia Sul-Goiana Km-01, CEP 75901-970 Rio Verde, GO. E-mail: fredalsoares@hotmail.com
\end{abstract}

Resumo - O objetivo deste trabalho foi avaliar alterações nas trocas gasosas e nos conteúdos de carboidratos e compostos nitrogenados, em pinhão-manso (Jatropha curcas) irrigado com águas residuária e salina. Empregou-se o delineamento em blocos ao acaso, com quatro tratamentos e quatro repetições: irrigação plena com água de abastecimento a $0,6 \mathrm{dS} \mathrm{m}^{-1}$ (controle); irrigação plena com água salinizada a 2,4 $\mathrm{dS} \mathrm{m}^{-1}$ (SAL); e irrigação com água residuária de esgoto, plena (R100) e a 50\% da capacidade de campo (R50). O tratamento R50 reduziu fortemente as trocas gasosas e a área foliar, comparado ao controle, seguido pelos tratamentos SAL e R100. A redução na fotossíntese diminuiu o nível de sacarose nas folhas, nos quatro tratamentos. Os teores de açúcares solúveis aumentaram nos tratamentos R50, SAL e R100, enquanto o conteúdo de amido permaneceu praticamente inalterado. Os conteúdos de prolina e glicina betaína aumentaram nos três tratamentos, mas a última foi mais importante, em termos quantitativos, como protetor celular e osmótico. A irrigação plena com água residuária induz efeitos similares aos causados pela irrigação com água salina. A irrigação limitada com água residuária causa estresse agudo às plantas, provavelmente pela combinação de deficiência hídrica e acúmulo de solutos no solo.

Termos para indexação: Jatropha curcas, estresse salino, glicina betaína, prolina, salinização do solo, trocas gasosas.

\section{Gas exchange and contents of carbohydrates and nitrogen compounds in physic nut irrigated with saline water and wastewater}

\begin{abstract}
The objective of this work was to evaluate the changes in gas exchange and in the contents of carbohydrates and nitrogen compounds in physic nut (Jatropha curcas) irrigated with wastewater and saline water. The experiment was carried out in a randomized block design, with four treatments and four replicates: irrigation with tap water at $0.6 \mathrm{dS} \mathrm{m}^{-1}$ (control); full irrigation with saline tap water at $2.4 \mathrm{dS} \mathrm{m}^{-1}$ (Salt); and irrigation with wastewater at full (W100) or at 50\% field capacity (W50). The W50 treatment remarkably reduced gas exchange and leaf area in comparison to the control, followed by Salt and W100 treatments. Reduction in photosynthesis lowered leaf-sucrose content in the four treatments. Total soluble sugar contents increased in W50, Salt, and W100 treatments, while starch content remained almost unaltered. Proline and glycine betaine contents increased in these treatments, but the latter was quantitatively more important as osmotic and cellular protector. Full irrigation with wastewater induces similar effects to the ones caused by irrigation with saline water. Irrigation with limited amounts of wastewater caused an acute stress to plants, probably due to a combination of water deficit and solute accumulation in the soil.
\end{abstract}

Index terms: Jatropha curcas, saline stress, glycine betaine, proline, soil salinization, gas exchange.

\section{Introdução}

O pinhão-manso (Jatropha curcas L.) é comum em regiões áridas e semiáridas da América do Sul e em regiões tropicais de todo o mundo (Kumar et al.,
2008). A espécie apresenta em suas sementes alto teor de óleo de boa qualidade, o qual pode ser facilmente convertido em biocombustível (Silva et al., 2010). Esta espécie cresce naturalmente em áreas marginais, frequentemente submetidas à seca, solos de baixa

Pesq. agropec. bras., Brasília, v.47, n.10, p.1428-1435, out. 2012 
fertilidade e altas temperaturas, condições em que a maioria das outras espécies agrícolas não seria capaz de sobreviver (Francis et al., 2005).

Para ampliar a fronteira agrícola para áreas marginais, são necessários o emprego de culturas resistentes e a utilização sustentável dos recursos disponíveis, como as águas de qualidade inferior, residuárias e salinas. Para mitigar a escassez de recursos hídricos em regiões semiáridas tropicais, vários estudos têm mostrado a possibilidade de utilização dessas águas como alternativa para a agricultura (Ferreira et al., 2005; Kumar et al., 2008; Sousa et al., 2011).

A salinidade e o deficit hídrico afetam negativamente a assimilação fotossintética de $\mathrm{CO}_{2}$ e diminuem o crescimento e a produtividade das plantas (Munns et al., 2006; Flexas et al., 2007). Pode causar também um desbalanço do perfil de carboidratos e de compostos nitrogenados (Silva et al., 2010). Em geral, há diminuição dos níveis de sacarose e aumento do conteúdo de açúcares redutores, enquanto o conteúdo de amido pode aumentar ou diminuir, a depender da espécie (Paul \& Foyer, 2001).

A acumulação de compostos orgânicos osmoticamente compatíveis em condições de estresse reflete a capacidade de algumas espécies de se ajustarem osmoticamente a condições adversas (Silva et al., 2010). A acumulação desses solutos provoca a diminuição do potencial hídrico da planta, facilita a absorção de água e protege as estruturas celulares (Munns et al., 2006). Em plantas jovens de pinhão-manso expostas ao estresse hídrico, há significativa contribuição de açúcares solúveis e compostos inorgânicos $\left(\mathrm{Na}^{+}, \mathrm{K}^{+}\right.$ e $\mathrm{Cl}^{-}$) no ajustamento osmótico (Silva et al., 2010). Quando expostas ao estresse salino, essas plantas utilizaram intensamente os próprios íons salinos $\mathrm{Na}^{+} \mathrm{e}$ $\mathrm{Cl}^{-}$, junto com a glicina betaína, para o ajustamento ou redução do potencial osmótico (Silva et al., 2009).

A utilização de águas residuárias e salinas pode ser uma alternativa viável para a expansão sustentável do cultivo de pinhão-manso e de outras culturas no Semiárido brasileiro. Apesar de alguns trabalhos terem demonstrado que essas plantas jovens de pinhão manso são relativamente sensíveis à salinidade (Silva et al., 2009, 2010), ainda são raras as pesquisas com plantas de pinhão-manso em fase de produção, nessas condições. Recentemente, Sousa et al. (2012a, 2012b) mostraram que essa espécie apresentou boa resposta à lâmina de reposição hídrica com água residuária tratada, proveniente de esgoto doméstico, enquanto a salinidade de água de irrigação prejudicou as plantas e provocou reduções na condutância estomática e nas taxas de transpiração e de fotossíntese, bem como aumento da temperatura foliar.

O objetivo deste trabalho foi avaliar alterações nas trocas gasosas e nos conteúdos de carboidratos e compostos nitrogenados, em pinhão-manso (Jatropha curcas) irrigado com águas residuária e salina.

\section{Material e Métodos}

O experimento foi realizado em casa de vegetação, em condições não controladas, na Universidade Federal de Campina Grande, PB (07015'18"S e $\left.35^{\circ} 52^{\prime} 28^{\prime \prime} \mathrm{W}\right)$. O clima é do tipo Csa, pela classificação de Köppen adaptada ao Brasil (Coelho \& Soncin, 1982). As plantas de pinhão-manso foram propagadas a partir de sementes fornecidas pela Fazenda Tamanduá, na Paraíba.

O trabalho foi conduzido com quatro tratamentos: irrigação plena, a 100\% da capacidade de campo (CC), com água de abastecimento a $0,6 \mathrm{dS} \mathrm{m}^{-1}$ (controle); irrigação, a 100\% da CC, com água salinizada a $2,4 \mathrm{dS} \mathrm{m}^{-1}$ (SAL); e irrigação, a 100 e a $50 \%$ da $\mathrm{CC}$, com água residuária de esgoto tratado (R100 e R50, respectivamente). Empregou-se o delineamento em blocos ao acaso, com quatro tratamentos e quatro repetições, e uma planta por parcela. As plantas foram cultivadas em recipientes de plástico de $200 \mathrm{~L}$ que serviram como lisímetro de drenagem. O solo utilizado foi classificado como Argissolo Acinzentado eutrófico (Santos et al., 2006), com textura franco-arenosa, não salino e não sódico, retirado da camada $0-30 \mathrm{~cm}$ e proveniente do distrito de São José da Mata, Campina Grande, PB. As características da água salinizada e da água residuária utilizadas no experimento, assim como o regime de irrigação e condução experimental, estão descritas em Sousa et al. (2012a, 2012b).

As variáveis analisadas nesta pesquisa são referentes ao quarto ano de produção do pinhão-manso. Ao final do terceiro ano de cultivo, as plantas foram submetidas a estresse hídrico contínuo por 35 dias, para induzir desfolhamento e posterior uniformização do estado de crescimento fisiológico das plantas. Posteriormente, foi colocado, em cada vaso, $1 \mathrm{~kg}$ de húmus de minhoca associado a aplicações anuais de: $80 \mathrm{~g}$ de $\mathrm{N}$ (uréia) por planta, $62 \mathrm{~g}$ de $\mathrm{K}_{2} \mathrm{O}$ (cloreto de potássio) por planta e $135 \mathrm{~g}$ de $\mathrm{P}_{2} \mathrm{O}_{5}$ (super fosfato simples), fracionados

Pesq. agropec. bras., Brasília, v.47, n.10, p.1428-1435, out. 2012 
mensalmente. À época das medições, valores médios de condutividade elétrica na água de drenagem (CEad) foram iguais a 6,25, 16,07, 19,42 e $17,71 \mathrm{dS} \mathrm{m}^{-1}$, para os tratamentos controle, SAL, R50 e R100, respectivamente. Considerando-se a relação $2 \times$ CEes $=$ CEad, recomendada por Ayers \& Westcot (1999), pode-se inferir que os solos dos vasos, nos respectivos tratamentos, apresentavam valores médios de condutividade elétrica no extrato de saturação (CEes) de 3,12, 8,03, 9,71 e 8,86 $\mathrm{dS} \mathrm{m}^{-1}$, respectivamente.

A área foliar foi estimada com base em amostra de, no mínimo, $25 \%$ do número de folhas da planta, pela metodologia proposta por Severino et al. (2007). As massas de folhas secas foram obtidas a partir da coleta de todas as folhas de cada planta, submetidas à secagem em estufa de circulação forçada de ar a $60^{\circ} \mathrm{C}$ por 72 horas.

As trocas gasosas $\left(\mathrm{P}_{\mathrm{N}}\right.$, taxa de assimilação de $\mathrm{CO}_{2} ; \mathrm{g}_{\mathrm{s}}$, condutância estomática; E, transpiração; $\mathrm{Ci}$, concentração intercelular de $\left.\mathrm{CO}_{2}\right)$ foram mensuradas com medidor portátil IRGA, modelo LCi System ADC, (Bioscientific Ltd. Hoddesdon, UK), na quarta folha totalmente expandida a partir do ápice da planta, abaixo da inflorescência. Nas medições, sempre realizadas entre 9 e $10 \mathrm{~h}$ da manhã, foram padronizadas as seguintes condições dentro da câmara do IRGA: densidade de fluxo de fótons fotossinteticamente ativos de $1.000 \mu \mathrm{mol} \mathrm{m} \mathrm{m}^{-2} \mathrm{~s}^{-1}$, temperatura de $28 \pm 1^{\circ} \mathrm{C}$; DPV de $1,0 \pm 0,2 \mathrm{kPa}$; e concentração parcial externa de $\mathrm{CO}_{2}$ ambiente de aproximadamente $38 \mathrm{~Pa}$.

Para as determinações químicas e bioquímicas, foram utilizados os limbos foliares de folhas normais, sadias - sem deficiência nutricional aparente ou ataque de pragas e doenças - localizadas entre a quarta e a quinta folhas abaixo da inflorescência, tendo-se coletado quatro folhas por planta em amostra composta. Para as determinações bioquímicas, após a coleta, as folhas foram imediatamente congeladas com $\mathrm{N}_{2}$ líquido e, em seguida, secas em liofilizador. Para as determinações dos teores de $\mathrm{Na}$ e K, as amostras foram secas em estufa de circulação forçada de ar a $60^{\circ} \mathrm{C}$ por 72 horas. Todos os materiais secos foram pesados, finamente triturados e armazenados para posterior utilização nas análises.

Para a determinação dos teores de $\mathrm{Na}$ e $\mathrm{K}$, as amostras foliares foram submetidas à extração em água deionizada fervente, por uma hora, em tubos fechados. Os teores dos elementos foram mensurados por fotometria de chama. A determinação dos açúcares solúveis totais foi realizada colorimetricamente, conforme Dubois et al. (1956). A extração foi realizada a partir de folhas previamente liofilizadas, em solução de MCW 12:5:3 (metanol:clorofórmio:água). Para a determinação do amido, foram realizadas duas extrações consecutivas do material liofilizado, tendose utilizado o mesmo extrator, a $80^{\circ} \mathrm{C}$ por $30 \mathrm{~min}$. Em seguida, foi realizado um novo ciclo de duas extrações consecutivas com ácido perclórico a 30\%, por $30 \mathrm{~min}$, a $25^{\circ} \mathrm{C}$, seguidas de centrifugações a 2.000 rotações $\mathrm{min}^{-1}$ por $10 \mathrm{~min}$. Os sobrenadantes das duas extrações consecutivas com ácido perclórico foram reunidos para a obtenção do extrato total, e aferidos com água destilada para $10 \mathrm{~mL}$. A partir desse extrato, foi realizada a determinação do amido conforme Dubois et al. (1956). Para a determinação de sacarose, o material vegetal liofilizado foi homogeneizado em solução de MCW 12:5:3 e mantido sob agitação por 30 min. As leituras de absorbância foram realizadas em espectrômetro, a $620 \mathrm{~nm}$ (Van Handel, 1968). O conteúdo de açúcares redutores foi estimado por meio da diferença entre o teor de sacarose e o conteúdo de açúcares solúveis totais, mensurado no mesmo extrato utilizado para sacarose, pelo método de Dubois et al. (1956). Os carboidratos totais não estruturais foram estimados por meio do somatório dos açúcares solúveis totais mais o amido.

As determinações de aminoácidos livres (Yemm \& Cocking, 1955), nitrato (Cataldo et al., 1975) e amônio (Wheatherburn, 1967) foram realizadas após extração com água deionizada a $100^{\circ} \mathrm{C}$. A determinação do nitrogênio total foi realizada conforme Baethgen \& Allen (1989). O conteúdo de prolina conforme Bates et al. (1973) e o de glicina betaína de acordo com a metodologia proposta por Grieve \& Grattan (1983).

Os resultados foram analisados mediante análise de variância, e as médias foram comparadas pelo teste de Tukey a $5 \%$ de probabilidade.

\section{Resultados e Discussão}

As plantas de pinhão-manso expostas a condições de estresse salino $-2,4 \mathrm{dS} \mathrm{m}^{-1}$ de condutividade elétrica na água de irrigação e $8,08 \mathrm{dS} \mathrm{m}^{-1}$ no extrato de saturação e irrigação plena (R100) e deficitária (R50, 50\% da CC) com água residuária de esgoto tratado apresentaram decréscimos significativos na área foliar e massa de folhas secas, em comparação ao controle (Figura 1). 
O tratamento R50 causou intensa redução $(80 \%)$ da área foliar em comparação ao controle, enquanto os tratamentos SAL e R100 causaram reduções de aproximadamente 43 e $32 \%$, respectivamente. Como esperado, a massa de folhas mostrou a mesma tendência que área foliar, nos quatro tratamentos. A taxa de assimilação de $\mathrm{CO}_{2}$ também apresentou comportamento semelhante ao dessas variáveis, o que indica que os efeitos negativos dos tratamentos SAL, R100 e R50 sobre o crescimento foram, em grande parte, resultantes da diminuição na fotossíntese (Chaves et al., 2009).

Os três parâmetros de trocas gasosas avaliados $\left(\mathrm{P}_{\mathrm{N}}\right.$, $\mathrm{g}_{\mathrm{s}}$ e E) mostraram estreita relação entre si, nos quatro tratamentos, enquanto a concentração intracelular de $\mathrm{CO}_{2}$ (Ci) apresentou comportamento inverso ao desses parâmetros. No tratamento R50, o valor de Ci foi superior ao do controle, enquanto nos tratamentos R100 e SAL os valores foram aproximadamente quatro vezes menores do que os do controle (Figura 1). Esses resultados evidenciam que o tratamento R50 sofreu efeitos diferentes daqueles apresentados por R100 e SAL, quanto às trocas de $\mathrm{CO}_{2}$ e à eficiência de carboxilação. Valores muito baixos de $\mathrm{P}_{\mathrm{N}} / \mathrm{Ci}$ (eficiência de carboxilação instantânea), como os apresentados em R50, evidenciam que houve limitações estomáticas e não estomáticas (bioquímicas) na assimilação fotossintética do $\mathrm{CO}_{2}$. Esse processo é muito comum durante períodos prolongados de restrição hídrica na planta (Flexas \& Medrano, 2002). É interessante notar que as relações $\mathrm{P}_{\mathrm{N}} / \mathrm{Ci}$ dos tratamentos $\mathrm{R} 100$ e SAL foram similares e aproximadamente duas vezes superiores às do controle, o que mostra que, nesses dois tratamentos, a limitação da fotossíntese $\left(\mathrm{P}_{\mathrm{N}}\right)$ foi provavelmente consequência da restrição estomática. Portanto, a restrição hídrica imposta pelo tratamento R50 foi capaz de causar danos bioquímicos no aparato fotossintético. Os mecanismos bioquímicos de modulação da assimilação de $\mathrm{CO}_{2}$ por restrição hídrica ainda não são bem conhecidos, mas reduções na expressão e atividade de Rubisco têm sido relatadas (Flexas \& Medrano, 2002; Chaves et al., 2009).

A despeito das fortes restrições à fotossíntese causada pelo tratamento R50, as plantas deste tratamento apresentaram valores mais elevados do quociente entre a taxa de assimilação de $\mathrm{CO}_{2}$ e a transpiração, e da eficiência de uso instantâneo de água (EUIA) calculada a partir dos dados da Figura 1. Os tratamentos R100 e SAL mostraram valores similares de EUIA, mas superiores aos do controle. Os valores maiores de EUIA foram associados a menor condutância estomática, o que evidencia que as plantas de pinhão-manso têm um mecanismo eficiente de restrição de perda de água pelos estômatos, conforme reportado recentemente em plantas jovens expostas à deficiência hídrica severa (Silva et al., 2012).

É possível que os efeitos adversos dos três tratamentos (SAL, R50 e R100) sejam advindos de diferentes mecanismos nas plantas. O tratamento SAL, claramente, causou estresse salino, evidenciado pelos níveis altos de $\mathrm{Na}$ nas folhas e de condutividade elétrica no extrato de saturação (Tabela 1). A quantidade de água no tratamento R50 já não seria suficiente para atender a demanda hídrica nas plantas e, além disso, o tratamento resultou em acúmulo de solutos no solo, conforme indicado pela baixíssima condutância estomática (Figura 1) e pela alta condutividade elétrica no extrato de saturação (Tabela 1). No entanto, o tratamento R100
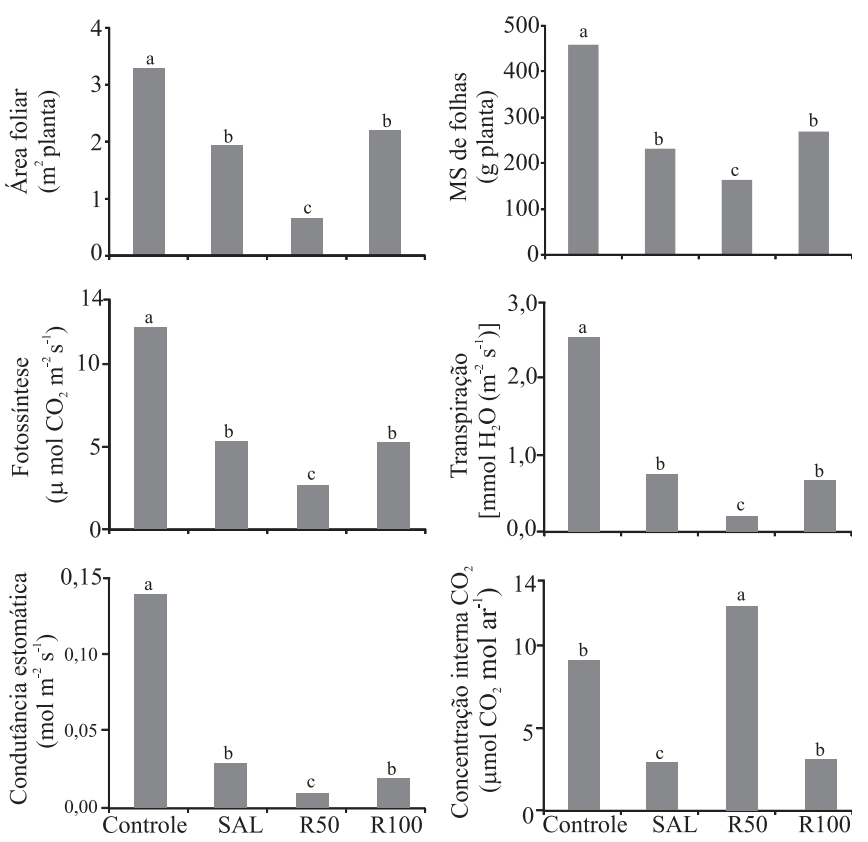

Figura 1. Área foliar, massa de matéria seca (MS) de folhas, fotossíntese, transpiração, condutância estomática e eficiência instantânea do uso de água, em plantas adultas de pinhão-manso expostas a quatro tratamentos: controle, irrigação plena de abastecimento a $0,6 \mathrm{dS} \mathrm{m}^{-1}$; SAL, irrigação plena com água salinizada a $2,4 \mathrm{dS} \mathrm{m}^{-1} ; \mathrm{R} 50 \mathrm{e}$ R100, irrigação com água residuária de esgoto, plena e a $50 \%$ da capacidade de campo, respectivamente. Médias seguidas de letras iguais não diferem pelo teste de Tukey, a 5\% de probabilidade. 
causou diminuição no crescimento das folhas e na fotossíntese provavelmente pelo acúmulo de excesso de solutos no solo (Tabela 1). É importante ressaltar que a água residuária pode também conter materiais tóxicos, tais como metais pesados, os quais poderiam agravar os efeitos dos tratamentos.

De acordo com Silva et al. (2009), os valores de $\mathrm{Na}$ nas folhas e os de condutividade elétrica no solo (Tabela 1), obtidos nos tratamentos SAL e R100, seriam suficientemente elevados para causar estresse salino nas plantas de pinhão-manso. Estudos anteriores mostraram que níveis crescentes de salinidade e de condutividade elétrica no extrato de saturação, causados por irrigação com água salina e residuária, restringem o crescimento em plantas adultas de pinhão-manso (Sousa et al., 2012a, 2012b). Todavia, outros trabalhos mostraram que salinidade e seca causam aumentos nas concentrações de prolina e glicina betaína em plantas jovens de pinhão-manso, mas concentrações de prolina ainda insuficientes para exercerem um possível papel de regulação osmótica (Silva et al., 2009, 2010).

De modo geral, as plantas dos tratamentos R100 e SAL apresentaram respostas semelhantes quanto às trocas gasosas e ao crescimento das folhas. Como esses tratamentos também apresentaram valores semelhantes de condutividade elétrica, no extrato de saturação e de $\mathrm{Na}^{+}$nas folhas (Tabela 1), é possível supor que o fator osmótico tenha sido preponderante nos dois tratamentos. É interessante notar que, no tratamento R100, as plantas apresentaram crescimento de folhas e parâmetros de trocas gasosas bem acima dos observados em R50, o que evidencia o efeito positivo da água residuária, a despeito de ser uma água considerada marginal para uso agrícola. É provável que

Tabela 1. Teores de $\mathrm{Na}$ e $\mathrm{K}$ nas folhas e condutividade elétrica no extrato de saturação (CEes), em pinhão-manso irrigado com água salina e efluente doméstico durante o quarto ano de cultivo ${ }^{(1)}$.

\begin{tabular}{lccc}
\hline Tratamento $^{(2)}$ & \multicolumn{1}{c}{$\mathrm{Na}^{+}$} & $\mathrm{K}^{+}$ & $\begin{array}{c}\mathrm{CEes} \\
\left(\mathrm{dS} \mathrm{m}{ }^{-1}\right)\end{array}$ \\
\hline Controle & $----------\left(\mathrm{mmol} \mathrm{kg}^{-1} \mathrm{MS}\right)---------$ & 3,12 \\
SAL & $778,43 \mathrm{c}$ & $448,72 \mathrm{~b}$ & $8,03 \mathrm{a}$ \\
R50 & $740,20 \mathrm{~b}$ & $384,62 \mathrm{c}$ & $9,71 \mathrm{a}$ \\
R100 & $437,91 \mathrm{~d}$ & $711,54 \mathrm{a}$ & $8,86 \mathrm{a}$ \\
\hline
\end{tabular}

(1)Letras diferentes representam diferença significativa entre os tratamentos, para cada variável, pelo teste de Tukey, a $5 \%$ de probabilidade. ${ }^{(2)}$ Controle, irrigação plena de abastecimento a $0,6 \mathrm{dS} \mathrm{m}^{-1}$; SAL, irrigação plena com água salinizada a $2,4 \mathrm{dS} \mathrm{m}^{-1} ; \mathrm{R} 50$ e R100, irrigação com água residuária de esgoto, plena e a $50 \%$ da capacidade de campo, respectivamente. o bom suprimento de água, associado ao conteúdo de macronutrientes, possa ter compensado parcialmente os efeitos adversos causados pela presença de excesso de sais e de elementos tóxicos (Sousa et al., 2011).

Diversos trabalhos têm mostrado que o estresse salino e a seca reduzem intensamente a fotossíntese e o crescimento foliar das plantas em geral (Chaves et al., 2009). Os carboidratos oriundos da fotossíntese desempenham papel importante no suprimento de esqueletos de carbono para a síntese de diversos compostos, tais como aminoácidos, outros solutos nitrogenados e proteínas. As relações entre mudanças na fotossíntese, perfil de carboidratos e estresse é complexa, uma vez que o metabolismo de carboidratos, após o processo fotossintético, pode tomar diversas rotas metabólicas (McCormick et al., 2008).

As concentrações de açúcares solúveis totais (AST) e de açúcares redutores (AR) (Figura 2) foram aumentadas nas plantas sob estresses salino e hídrico (SAL e R50), mas diminuídas nas plantas plenamente irrigadas com água residuária (R100), em comparação ao controle. Os perfis de AST e AR foram semelhantes nos quatro tratamentos, enquanto as concentrações de sacarose mostram relação positiva com a fotossíntese nos quatro tratamentos. Esses resultados indicam que há predomínio de glicose e frutose na fração de AST, pois esses são os açúcares redutores mais importantes nas plantas (Paul \& Foyer, 2001; McCormick et al., 2008). As concentrações de sacarose foram relativamente baixas nas folhas dos quatro tratamentos, possivelmente porque foram determinadas nas folhas adjacentes aos frutos em formação.

Frequentemente, as concentrações de AST são aumentadas em plantas sob condições de estresse, principalmente em razão do aumento na atividade das amilases (Paul \& Foyer, 2001). Comparadas às do controle, as concentrações de sacarose diminuíram nos três tratamentos de restrição fotossintética, e tal decréscimo foi maior nas plantas R50. A redução dos níveis de sacarose foi relativamente bem relacionada com os níveis de fotossíntese (Figuras 1 e 2), a despeito da frequente redução desse açúcar pelo decréscimo na migração para outros tecidos a partir das folhas (McCormick et al., 2008).

Os níveis de amido diminuíram somente no tratamento R50, o que evidencia os fortes efeitos da deficiência hídrica sobre a restrição fotossintética e, possívelmente, induziram um aumento na atividade 
de amilases (Silva et al., 2012). A redução intensa na taxa de assimilação de $\mathrm{CO}_{2}$ foi acompanhada de forte decréscimo dos conteúdos de sacarose e aumento dos níveis de açúcares redutores, no tratamento R50. Alguns experimentos têm mostrado que a acumulação de hexoses pode modular negativamente a fotossíntese, por meio da diminuição da expressão de genes ligados à assimilação de $\mathrm{CO}_{2}$ (McCormick et al., 2008). No conjunto, os resultados de perfil de carboidratos são fisiologicamente consistentes com a presença de
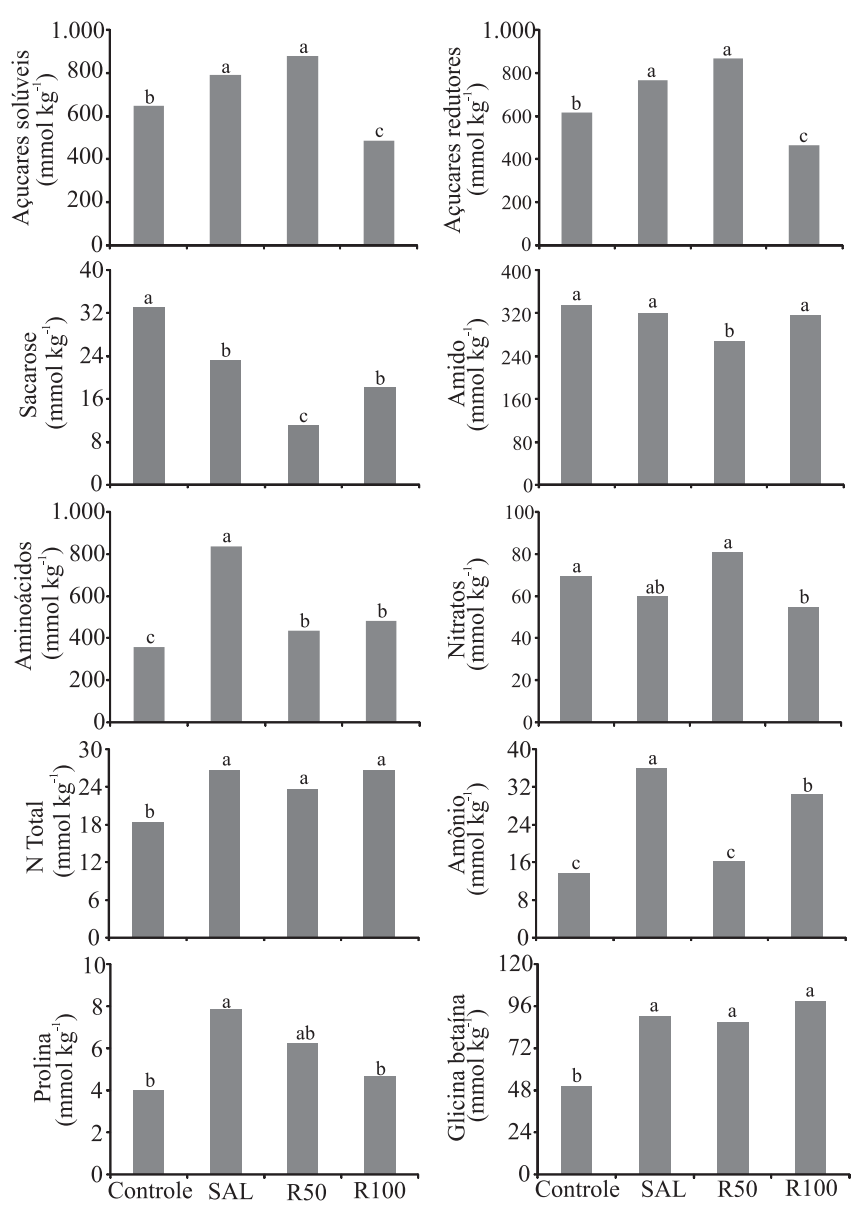

Figura 2. Conteúdos de açúcares solúveis totais, açúcares redutores, sacarose, amido, prolina, aminoácidos, nitrato, nitrogênio total, amônio e glicina betaína, na massa de matéria seca de folhas de plantas adultas de pinhão-manso expostas a quatro tratamentos: controle, irrigação plena de abastecimento a $0,6 \mathrm{dS} \mathrm{m}^{-1}$; SAL, irrigação plena com água salinizada a 2,4 dS m-1; R50 e R100, irrigação com água residuária de esgoto, plena e a $50 \%$ da capacidade de campo, respectivamente. Médias seguidas de letras iguais não diferem pelo teste de Tukey, a 5\% de probabilidade. estresse nos tratamentos R50, SAL e R100. Esses dados indicam que o nível de sacarose nas folhas, junto com a taxa de fotossíntese, parecem ser um bom indicador do estado fisiológico de plantas de pinhão-manso em fase produtiva.

Os compostos nitrogenados estão envolvidos com diversos processos fisiológicos e com a produtividade das plantas. No entanto, o perfil desses compostos pode ser alterado por mudanças ambientais, e o nível de alguns desses compostos pode funcionar tanto como indicador de estresse como do estado nutricional e fisiológico da planta (Silveira et al., 2003). É importante notar que os tratamentos R50 e R100 mostraram perfil de compostos nitrogenados muito semelhantes entre si, especialmente quanto aos conteúdos de aminoácidos, N-total e glicina betaína, que são as formas quantitativamente mais importantes em folhas de pinhão-manso (Silva et al., 2010). As formas nitrato, amônio e prolina apresentaram baixas concentrações, que além disso variam em função das condições ambientais (Figura 1).

Os conteúdos de N-total, glicina betaína e aminoácidos foram maiores nos tratamentos de restrição de crescimento foliar, especialmente em R50 e R100 (Figura 2). Esse resultado pode ter algumas razões fisiológicas, tais como: efeito de concentração, em consequência da restrição de crescimento; desbalanço entre suprimento de açucares e assimilação de nitrato; e indução na via de síntese de glicina betaína pela redução no potencial hídrico.

Deve-se destacar o aumento nas concentrações de prolina e glicina betaína nos tratamentos que causaram restrição de crescimento foliar e de trocas gasosas. Em especial, as concentrações alcançadas por glicina betaína, um soluto compatível e protetor celular bastante eficaz, foram bem mais elevadas do que as de prolina, como já havia sido observado em plantas jovens de pinhão-manso expostas à salinidade e deficiência hídrica (Silva et al., 2009, 2010). A glicina betaína está envolvida com o ajustamento osmótico, a proteção de estruturas celulares e a proteção antioxidante (Silva et al., 2010). Portanto, a acumulação desse soluto pode ter contribuído, pelo menos em parte, para a proteção das plantas nas condições adversas de potencial osmótico no solo, enquanto que, em termos quantitativos, a prolina deve ter tido um papel secundário.

A análise conjunta dos resultados permite sugerir que a irrigação com água salina causa efeitos deletérios, semelhantes aos dairrigação comágua residuária, quanto 
a trocas gasosas e crescimento foliar, em plantas adultas de pinhão-manso. No entanto, a irrigação deficitária com R50 causa fortes restrições à fisiologia da planta, provavelmente, por combinar efeitos de deficiência hídrica com acumulação excessiva de solutos no solo. Os resultados também permitem levantar questões sobre a sensibilidade de pinhão-manso à salinidade e à deficiência hídrica, isoladas ou combinadas, uma vez que o nível inicial de salinidade no tratamento SAL foi relativamente baixo, a despeito de a água de drenagem ter apresentado valores de $8,03 \mathrm{dS} \mathrm{m}^{-1}$ ao final do experimento.

\section{Conclusões}

1. O uso de irrigação com água salina, associado ao aumento da condutividade elétrica do extrato do solo, causa reduções da fotossíntese, diminuição de crescimento e alterações nos perfis de carboidratos e compostos nitrogenados nas folhas.

2. O emprego de lâmina deficitária de irrigação com água residuária causa intensa redução na fotossíntese e no crescimento das plantas, além de alterações nos perfis de carboidratos e compostos nitrogenados nas folhas.

3. O fornecimento de lâmina adequada de irrigação com água residuária causa danos à fotossíntese e ao crescimento das folhas comparáveis aos da irrigação com água salina.

\section{Agradecimentos}

Ao Conselho Nacional de Desenvolvimento Científico e Tecnológico e ao Instituto Nacional de Ciência e Tecnologia em Salinidade, por auxílio financeiro e bolsas concedidos.

\section{Referências}

AYERS, R.S.; WESTCOT, D.W. A qualidade da água na agricultura. 2.ed. Campina Grande: UFPB, 1999. 218p. (Estudos FAO. Irrigação e drenagem, 29).

BAETHGEN, W.E.; ALLEN, M.M. A manual colorimetric procedure for measuring ammonium nitrogen in soil and plant Kjedahl digests. Communications in Soil Science and Plant Analysis, v.20, p.961-969, 1989.

BATES, L.S. Rapid determination of free proline for water stress studies. Plant and Soil, v.39, p.205-207, 1973.

CATALDO, D.A.; HAROOM, M.; SCHRADER, L.E.; YOUNGS, V.L. Rapid colorimetric determination of nitrate in plant tissue by nitration of salicylic acid. Communications in Soil Science and Plant Analysis, v.6, p.71-80, 1975.

CHAVES, M.M.; FLEXAS, J.; PINHEIRO, C. Photosynthesis under drought and salt stress: regulation mechanisms from whole plant to cell. Annals of Botany, v.103, p.551-560, 2009.

COELHO, M.A.; SONCIN, N.B. Geografia do Brasil. São Paulo: Moderna, 1982. 368p.

DUBOIS, M.; GILLIES, K.A.; HAMILTON, J.K.; REBERS, P.A.; SMITH, F. Colorimetric method for determination of sugars and related substances. Analytical Chemistry, v.28, p.350-356, 1956.

FERREIRA, O.E.; BELTRÃO, N.E. de M.; KONIG, A. Efeitos da aplicação de água residuária e nitrogênio sobre o crescimento e produção do algodão herbáceo. Revista Brasileira de Oleaginosas e Fibrosas, v.9, p.893-902, 2005.

FLEXAS, J.; DIAZ-ESPEJO, A.; GALMÉS, J.; KALDENHOFF, R.; MEDRANO, H.; RIBAS-CARBO, M. Rapid variations of mesophyll conductance in response to changes in $\mathrm{CO}_{2}$ concentration around leaves. Plant Cell and Environment, v.30, p.1284-1298, 2007.

FLEXAS, J.; MEDRANO, H. Drought-inhibition of photosynthesis in C3 plants: stomatal and non-stomatal limitations revisited. Annals of Botany, v.89, p.183-189, 2002.

FRANCIS, G.; EDINGER, R.; BECKER, K. A concept for simultaneous wasteland reclamation, fuel production, and socio-economic development in degraded areas in India: need, potential and perspectives of Jatropha plantations. Nature Resources Forum, v.29, p.12-24, 2005.

GRIEVE, C.M.; GRATTAN, S.R. Rapid assay for determination of water-soluble quaternary ammonium-compounds. Plant and Soil, v.70, p.303-307, 1983.

KUMAR, N.; SUDHEER, D.V.N.; PAMIDIMARRI, M.K.; BORICHA, G.; MUPPALA, P.R. Effects of $\mathrm{NaCl}$ on growth, ion accumulation, protein, proline contents and antioxidant enzymes activity in callus cultures of Jatropha curcas. Biologia, v.63, p.378-382, 2008.

MCCORMICK, A.J.; CRAMER M.D.; WATT, D.A. Differential expression of genes in the leaves of sugarcane in response to sugar accumulation. Tropical Plant Biology, v.1, p.142-158, 2008.

MUNNS, R.; JAMES, R.A.; LÄUCHLI, A. Approaches to increasing the salt tolerance of wheat and other cereals. Journal of Experimental Botany, v.57, p.1025-1043, 2006.

PAUL, M.J.; FOYER, C.H. Sink regulation for photosynthesis. Journal of Experimental Botany, v.52, p.1383-1400, 2001.

SANTOS, H.G. dos; JACOMINE, P.K.T.; ANJOS, L.H.C. dos; OLIVEIRA, V.A. de; OLIVEIRA, J.B. de; COELHO, M.R.; LUMBRERAS, J.F.; CUNHA, T.J.F. (Ed.). Sistema brasileiro de classificação de solos. 2.ed. Rio de Janeiro: Embrapa Solos, 2006. 306p.

SEVERINO, L.S.; VALE, L.S. do; BELTRÃO, N.E. de M. A simple method for measurement of Jatropha curcas leaf area. Revista Brasileira de Oleaginosas e Fibrosas, v.11, p.9-14, 2007.

SILVA, E.N. da; FERREIRA-SILVA, S.L.; VIÉGAS, R.A.; SILVEIRA, J.A.G. The role of organic and inorganic solutes in the 
osmotic adjustment of drought-stressed Jatropha curcas plants. Environmental and Experimental Botany, v.69, p.279-285, 2010.

SILVA, E.N. da; RIBEIRO, R.V.; FERREIRA-SILVA, S.L.; VIEIRA, S.A.; PONTE, L.A.F.; SILVEIRA, J.A.G. Coordinate changes in photosynthesis, sugar accumulation and antioxidative enzymes improve the performance of Jatropha curcas plants under drought stress. Biomass and Bioenergy, v.45, p.270-279, 2012.

SILVA, E.N. da; SILVEIRA, J.A.G.; FERNANDES, C.R.F.; LIMA, C.S. de; VIÉGAS, R.A. Contribuição de solutos orgânicos e inorgânicos no ajustamento osmótico de pinhão-manso submetido à salinidade. Pesquisa Agropecuária Brasileira, v.44, p.437-445, 2009.

SILVEIRA, J.A.G.; VIÉGAS, R. de A.; ROCHA, I.M.A. da; MOREIRA, A.C. de O.M.; MOREIRA, R. de A.; OLIVEIRA, J.T.A. Proline accumulation and glutamine synthetase activity are increased by salt-induced proteolysis in cashew leaves. Journal of Plant Physiology, v.160, p.115-123, 2003.
SOUSA, A.E.C.; GHEYI, H.R.; SOARES, F.A.L.; MEDEIROS, E.P. de; NASCIMENTO, E.C.S. Teor de óleo no pinhão-manso em função de lâminas de água residuária. Pesquisa Agropecuária Brasileira, v.46, p.108-111, 2011.

SOUSA, A.E.C.; GHEYI, H.R.; SOARES, F.A.L.; NASCIMENTO, E.C.S.; ANDRADE, L.O. de. Biometria e desenvolvimento de pinhão manso com diferentes laminas de água residuaria e adubação fosfatada. Revista Caatinga, v.25, p.119-127, 2012a.

SOUSA, A.E.C.; LACERDA, C.F. de; GHEYI, H.R.; SOARES, F.A.L.; UYEDA, C.A. Teores de nutrientes foliares e respostas fisiológicas em pinhão manso submetido a estresse salino e adubação fosfatada. Revista Caatinga, v.25, p.144-152, 2012b.

VAN HANDEL, E. Direct microdetermination of sucrose. Analytical Biochemistry, v.22, p.280-283, 1968.

WHEATHERBURN, M.W. Phenol-hypochlorite reaction for determination of ammonia. Analytical Chemistry, v.39, p.971-974, 1967.

YEMM, F.W.; COCKING, E.F. The determination of amino acids with ninhydrin. Analyst, v.80, p.209-213, 1955.

Recebido em 29 de maio de 2012 e aprovado em 27 de setembro de 2012 